\title{
Feasibility Study on Tension Estimation Technique for Hanger Cables Using the FE Model-Based System Identification Method
}

\author{
Kyu-Sik Park, Taek-Ryong Seong, and Myung-Hyun Noh \\ Steel Solution Center, POSCO, 100 Songdogwahak-ro, Yeonsu-gu, Incheon 406-840, Republic of Korea \\ Correspondence should be addressed to Myung-Hyun Noh; mnoh@posco.com
}

Received 8 September 2014; Accepted 13 October 2014

Academic Editor: Sang-Youl Lee

Copyright (C) 2015 Kyu-Sik Park et al. This is an open access article distributed under the Creative Commons Attribution License, which permits unrestricted use, distribution, and reproduction in any medium, provided the original work is properly cited.

\begin{abstract}
Hanger cables in suspension bridges are partly constrained by horizontal clamps. So, existing tension estimation methods based on a single cable model are prone to higher errors as the cable gets shorter, making it more sensitive to flexural rigidity. Therefore, inverse analysis and system identification methods based on finite element models are suggested recently. In this paper, the applicability of system identification methods is investigated using the hanger cables of Gwang-An bridge. The test results show that the inverse analysis and systemic identification methods based on finite element models are more reliable than the existing string theory and linear regression method for calculating the tension in terms of natural frequency errors. However, the estimation error of tension can be varied according to the accuracy of finite element model in model based methods. In particular, the boundary conditions affect the results more profoundly when the cable gets shorter. Therefore, it is important to identify the boundary conditions through experiment if it is possible. The FE model-based tension estimation method using system identification method can take various boundary conditions into account. Also, since it is not sensitive to the number of natural frequency inputs, the availability of this system is high.
\end{abstract}

\section{Introduction}

Recently, the number of long-span bridges built in countries around the world is increasing. Of these long-span bridges, the suspension bridge uses stiffening girders that are attached to the main cables to support the load. In Korea, starting from the completion of the Nam-Hae Bridge in 1973, Yeongjong, Gwang-An, Yi Sun-Sin, and many other suspension bridges have been constructed, and Ulsan Bridge is also under construction as a suspension bridge. Most long-span bridges, such as suspension bridges, support their loads by means of cables. Therefore, it is necessary to estimate the tension of the cables to ensure structural safety during the construction phase and maintenance work after completion.

The most accurate means to estimate the tension on the cables is to use the load cells to collect the data directly. However, this is not an option in many cases due to the conditions in the field. Therefore, the most commonly used method is to extract the natural frequency from the measurements of acceleration signal and enter the extracted data into an equation that shows the relationship between the natural frequency and tension, and thus the cable tension can be estimated indirectly. The two most widely used methods are the taut string theory [1], which does not take the flexural rigidity into consideration, and the linear regression method [2], which regards the cable as a beam under the axial load and considers the flexural rigidity. Yun et al. [3] analyzed the influence of the effective length in the linear regression method, while Ahn et al. [4] used the static method, which requires the minimal amount of measurements compared to the dynamic methods, to calculate the tension on the hanger cables.

The estimation methods for tension using the existing dynamic method put the natural frequency values to the equation on the natural frequency and tension. Therefore, if the mathematical model used differs significantly from the actual structure, a significant error is unavoidable. In particular, in the case of hanger cables that transfer the load applied to the stiffening girder to the main cable, they are, in most cases, short cables with higher flexural rigidity. Also, 
due to the influence from the clamps and boundary conditions, errors are significant when the tension is estimated using the existing methods [5-7].

Therefore, to estimate the tension of shorter cables that are greatly influenced by flexural rigidity, like the hanger cables in a suspension bridge, some new methods are proposed that are based on the finite element model of the hanger cable. Kim et al. $[6,7]$ suggested formula-based inverse analysis method, which defines the errors between the calculated frequency using the analysis models and the frequency actually measured as the objective functions, and uses an optimized algorithm, the univariate search method and modal participation factor. Park et al. [5] suggested a vibrationbased system identification technique. This method uses the measured frequency as the input variable and the sensitivity equation to estimate the tension force through repeated calculations. Here, for a precise system identification of the hanger cables, a 3D finite element model is created, in which the physical properties including the tension force and the rigidities of hanger cable and clamp are set as the identification variables. The tension estimation technique for the hanger cable using the formula-based inverse analysis method was applied to the Gwang-An Bridge [6,7] while the tension estimation technique for the hanger cables based on the FE model-based system identification method was applied to the theoretical development [5], Yeongjong Bridge $[6,7]$, and the test sample [8].

In this paper, through the hanger cables of Gwang-An Bridge, the reliability of the system identification method based on the finite element model, which has higher applicability in tensile force estimation for short cables that are more sensitive to the flexural rigidity, is compared with that of the existing tension estimation methods, and its applicability is verified.

\section{Tension Estimation Methods}

2.1. Methods Using Mathematical Equation on the Natural Frequency and Tension. Many dynamic methods to estimate tensile force for cables have been developed considering dynamic characteristics and physical properties of cables. Among them, the flat taut string theory for cables that neglect both sag-extensibility and flexural rigidity is as follows:

$$
T=4 m L^{2}\left(\frac{f_{n}}{n}\right)^{2},
$$

where $f_{n}$ denotes the $n$th natural frequency in $\mathrm{Hz}$. The terms $T, m$, and $L$ denote tension force, mass density, and length of cable, respectively. The computation of tension force is straightforward with given measured frequency and mode number. However, the application of this formula is strictly limited to a flat long slender cable because it can not consider both sag-extensibility and bending stiffness of cables.

The modern cable theory [9] that takes account of the sag-extensibility without flexural rigidity requires additional information of the unstrained length of cable and involves solving a nonlinear characteristic equation by trial-anderror [10]. However, such additional information is often not available in practice, therefore the linear regression method [11] that considers cables as an axial load beam had been developed. This method considers the flexural rigidity but neglects the sag-extensibility as follows:

$$
\left(\frac{f_{n}}{n}\right)^{2}=\left(\frac{1}{4 m L^{2}}\right) T+\left(\frac{n^{2} \pi^{2}}{4 m L^{4}}\right) E I,
$$

where EI denotes the flexural rigidity of a cable. The unknown tension force and flexural rigidity can be identified through linear regression procedures with given measured frequency and mode number. This method is widely used by the field engineers because of its simplicity and speediness. To consider both sag-extensibility and bending stiffness, the practical formula [12] had been developed. But a priori data of the axial and flexural rigidities of the target cable system is required for the proper use of this practical method. However, the flexural rigidity of cable is often neither available nor valid because the shear and bending mechanisms of a cross section of cable could be different from those of beam.

2.2. Methods Using System Identification Approach Based on FE Model. In the process of estimating the tension using the finite element model based system identification method, the tensile force of cables is illustrated by the identification vector which is composed of several unknown parameters. In this study, the nine unknown parameters $x^{p}(p=$ $1, \ldots, 9)$ are used for identifying the tensile force in the system identification procedure and the identification vector is defined as

$$
\begin{aligned}
\mathbf{x} & =\left[\begin{array}{llll}
x^{1} & x^{2} & \cdots & x^{9}
\end{array}\right]^{\mathrm{T}} \\
& =\left[\begin{array}{lllllllll}
T & E A & E I_{y} & E I_{z} & G J & E A_{c} & E I_{y c} & E I_{z c} & G J_{c}
\end{array}\right]^{\mathrm{T}},
\end{aligned}
$$

where $T$ denotes the tensile force of a cable; $E A, E I_{y}\left(E I_{z}\right)$, and $G J$ denote axial, flexural, and torsional rigidities for a cable, respectively; and $E A_{c}, E I_{y c}\left(E I_{z c}\right)$, and $G J_{c}$ denote axial, flexural, and torsional rigidities for a clamp, respectively.

The identification vector for the $r$ th iteration in the sensitivity-based updating algorithm can be assumed as

$$
\begin{aligned}
& { }^{r} \mathbf{x}=\left[\begin{array}{lllll}
{ }^{r} x^{1} & { }^{r} & x^{2} & \ldots & { }^{r} x^{9}
\end{array}\right]^{\mathrm{T}}
\end{aligned}
$$

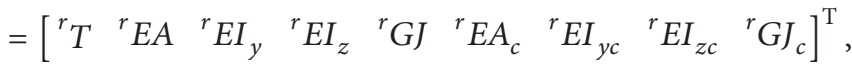

where ${ }^{r} \mathbf{x}$ mean the identification vector for the $r$ th iteration.
Then, the static displacement and tensile force distribution can be produced for the identification vector. In 
the next step, the natural frequency $\omega_{j}(j=1, \ldots, q)$ is determined from the finite element vibration analysis using the static displacement curve and tension distribution. Using the change in natural frequencies for different identification variables, the sensitivity matrix $(\mathbf{S})$ with $(q \times p)$ size can be determined approximately as follows:

$$
{ }^{r} \mathbf{S}=\left[\begin{array}{ccc}
\frac{\partial^{r} \omega_{1}}{\partial^{r} x_{1}} \frac{\partial^{r} x_{1}}{\partial^{r} \omega_{1}} & \cdots & \frac{\partial^{r} \omega_{1}}{\partial^{r} x_{p}} \frac{\partial^{r} x_{p}}{\partial^{r} \omega_{1}} \\
\vdots & \ddots & \vdots \\
\frac{\partial^{r} \omega_{q}}{\partial^{r} x_{1}} \frac{\partial^{r} x_{1}}{\partial^{r} \omega_{q}} & \cdots & \frac{\partial^{r} \omega_{q}}{\partial^{r} x_{p}} \frac{\partial^{r} x_{p}}{\partial^{r} \omega_{q}}
\end{array}\right] .
$$

Then, from the produced natural frequency data, the rate of change $\left(d^{r} \boldsymbol{\omega}\right)$ for the eigenvalue can be obtained as

$$
d^{r} \boldsymbol{\omega}=\left[\begin{array}{ccc}
\frac{\omega_{1}^{m}-{ }^{r} \omega_{1}^{c}}{{ }^{r} \omega_{1}^{c}} & \cdots & \frac{\omega_{q}^{m}-{ }^{r} \omega_{q}^{c}}{{ }^{r} \omega_{q}^{c}}
\end{array}\right]^{\mathrm{T}},
$$

where $\omega_{q}^{m}$ and ${ }^{r} \omega_{q}^{c}$ denote the qth mode's natural frequency measured from experiment or field test and the qth mode's frequency calculated from nonlinear finite element vibration analysis using ${ }^{r} x^{p}$ in the $r$ th iteration, respectively. Equation (6) can be rewritten in the vector form as

$$
d^{r} \boldsymbol{\omega}_{(q \times 1)}={ }^{r} \mathbf{S}_{(q \times p)} d^{r} \mathbf{x}_{(p \times 1)}
$$

Equation (7) is referred to as a linear sensitivity equation, and the rate of change for the identification vector by using (7) can be expressed as

$$
d^{r} \mathbf{x}={ }^{r} \mathbf{S}^{-1} d^{r} \boldsymbol{\omega}
$$

where ${ }^{r} \mathbf{S}^{-1}$ means the pseudoinverse matrix for ${ }^{r} \mathbf{S}$ and can be determined as

$$
{ }^{r} \mathbf{S}^{-1}=\left({ }^{r} \mathbf{S}^{\mathrm{T} r} \mathbf{S}\right){ }^{-1}{ }^{r} \mathbf{S}^{\mathrm{T}}
$$

Finally, the $p$ th identification variable in the $(r+1)$ th iteration can recalculated as

$$
\begin{aligned}
& { }^{r+1} x^{p}=\left(1+d^{r} x^{p}\right)^{r} x^{p}
\end{aligned}
$$

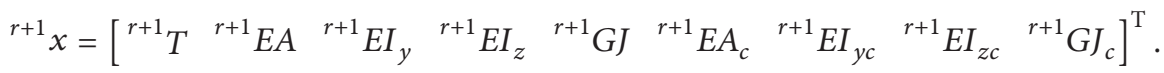

From (4) to (10), the loop is repeated until the convergence condition is satisfied. The convergence condition for the repetition analysis uses the square roots of the sum of square (SRSS) in the following:

$$
\begin{aligned}
& \mid \sqrt{\left.\left|\sum_{q=1}^{n}\right| \frac{\omega_{q}^{m}-\omega_{q}^{c}}{\omega_{q}^{m}} \mid \times 100\right)_{\text {step } r}^{2}} \\
& -\sqrt{\left(\sum_{q=1}^{n}\left|\frac{\omega_{q}^{m}-\omega_{q}^{c}}{\omega_{q}^{m}}\right| \times 100\right)_{\text {step } r+1}^{2}} \mid<0.01 .
\end{aligned}
$$

Finally, tensile force is determined from the identification variables holding at the termination stage and relevant natural frequencies can be determined through the finite element vibration analysis with the identification variables.

\section{Field Application: Hanger Cables of Gwang-An Bridge}

3.1. Measurement of the Vibration Signal. Located in Busan, Gwang-An Bridge is $900 \mathrm{~m}$ in total length (center span = $500 \mathrm{~m} ; 3$ spans and 2 hinges with each side $\operatorname{span}=200 \mathrm{~m}$ ) and a width of $24 \mathrm{~m}$. The height of the main tower (from sea level) is $116.5 \mathrm{~m}$. The hanger cables of Gwang-An Bridge become shorter as they approach the center of the span from the location of the main tower. In this paper, we examined the two hanger cables located on the beach side, as shown in Figure 1. At each sector, one hanger cable band holds two groups of hanger cables as shown in Figure 2. Of these, the acceleration signals of the hanger cable installed on the bridge side were measured.

On June 6, 2008, acceleration sensors were installed in a direction perpendicular to the hanger cables as shown in Figure 3, to measure the acceleration vibration signals of the hanger cables. Here, the acceleration sensors were installed at the height of the guardrail on the bridge to avoid missing the low vibration mode and to install them easily. The measurements were taken on holidays, which resulted in smaller amounts of traffic. Therefore, to get more reliable acceleration signals, vibration signals that lasted about 5 minutes over two measurement attempts were measured. Figure 4 shows how the field measurements scene.

For the four hanger cables, the sampling rates at ambient vibration were $1000 \mathrm{~Hz}$. To efficiently obtain vibration measurements, we used a $1 \mathrm{CH}$ AnyLogger, a dynamic wireless logger manufactured by Korea Maintenance Co., Ltd. Figure 5 shows the acceleration response signals obtained from the ambient vibrations in a direction perpendicular to the hanger cables and the PSD (power spectral density) of the response signal. When estimating the tensile force using the FE modelbased system identification method, the order and natural 


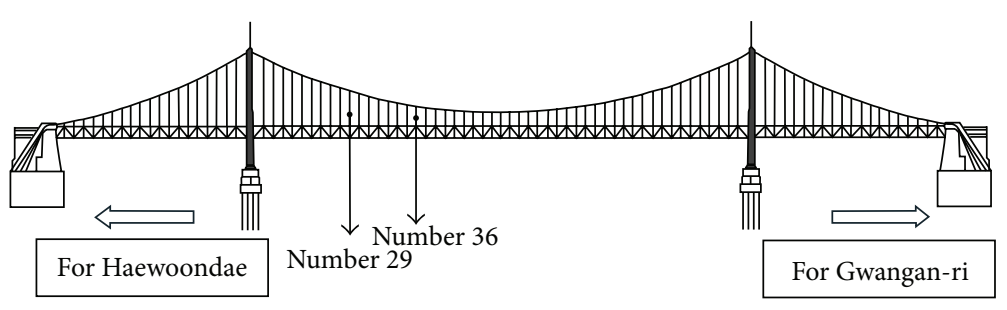

FIgURE 1: The locations of two hanger cables for measurement $[6,7]$.

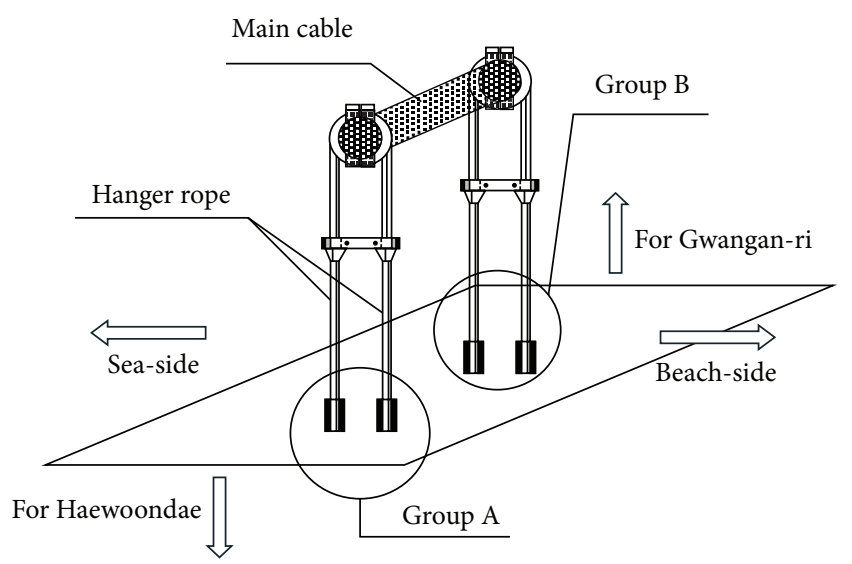

Figure 2: The groups of hanger cables $[6,7]$.

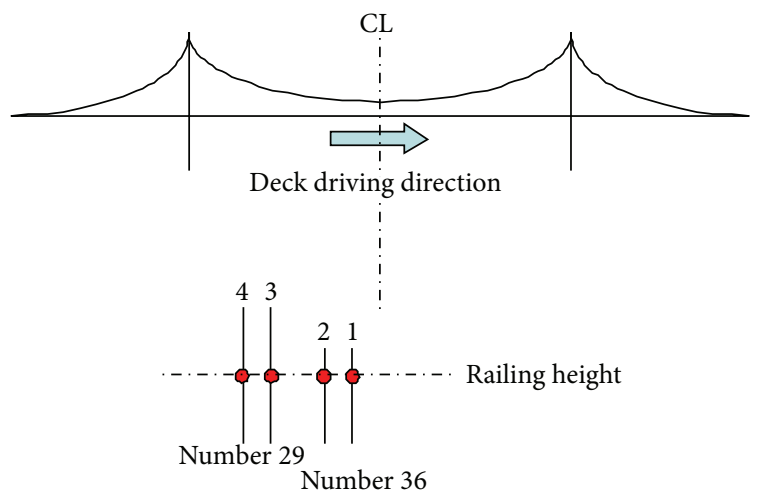

FIGURE 3: The locations for accelerometers attached on hanger cables.

frequency value of each vibration mode are important, while the absolute magnitude of acceleration signal and PSD do not significantly affect the results of tension estimation.

3.2. Finite Element Model. For the tensile force estimation method using the system identification technique, the hanger cables were modeled using three-dimensional linear elements that support the axial load to analyze the changes in natural frequency due to changes in tensile force. Here, the mass matrix was that of the frame elements, while the stiffness matrix is the sum of the stiffness matrix (Euler beam) of the normal frame elements and the geometric stiffness matrix in consideration of the influence of the tension.

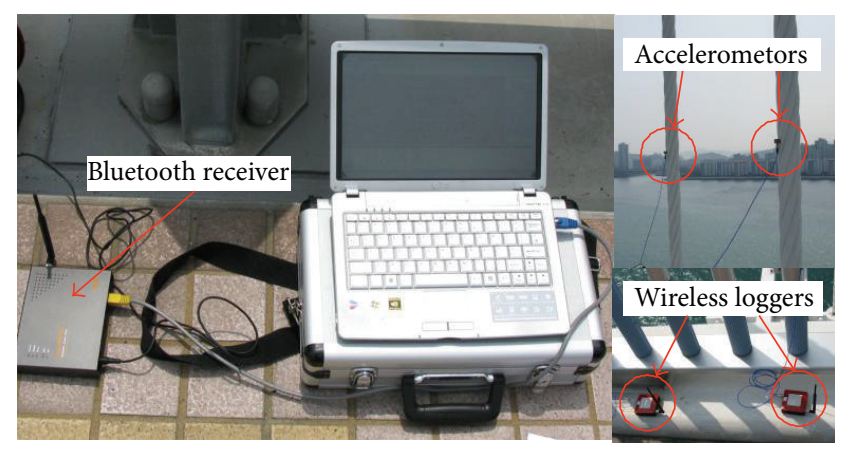

FIGURE 4: Acceleration measurements for hanger cables.

The lengths and physical properties of the hanger cables of Gwang-An Bridge assuming hinges at both ends are as shown in Table 1. Here, the diameter of the cable is the effective diameter equivalent to the effective cross-sectional area. The design tension was the tensile force mentioned in the design specifications of the hanger cable for the bridge and was assumed to be the initial tension when estimating the tension force using the FE model-based system identification method.

As for the clamps, the rectangular part other than the lower fixed sockets was modeled. Also, the length of the cable at the upper part of the clamp in the hanger cables was set at $1 \mathrm{~m}$ without variation. The cable at the bottom of the clamp was assumed to be the length minus the height $(0.5 \mathrm{~m})$ of the fixed socket at the bottom of the clamp to consider that some part of the cable is fixed by the clamps.

Figure 6 shows the finite element model of cable 29A. The hanger cables on both sides were modeled in 30 elements each, while the clamps were modeled in 3 elements.

3.3. Extraction of the Natural Frequency. As shown in Figure 5(b) the ambient vibration signals of the normal hanger cables are difficult to define due to the indistinctness of the measured vibration mode in many cases. Also in this study, only 1 instrument to measure acceleration at each hanger cable was installed. Therefore, it was not possible to extract the vibration mode through experiment. Therefore, the natural frequencies and the vibration mode were determined by comparing the results with measurements presented in the research by Kim et al. [6,7]. The natural frequencies extracted in this way for the hanger cables are as shown in Table 2. In this case, the natural frequency is determined as the average 

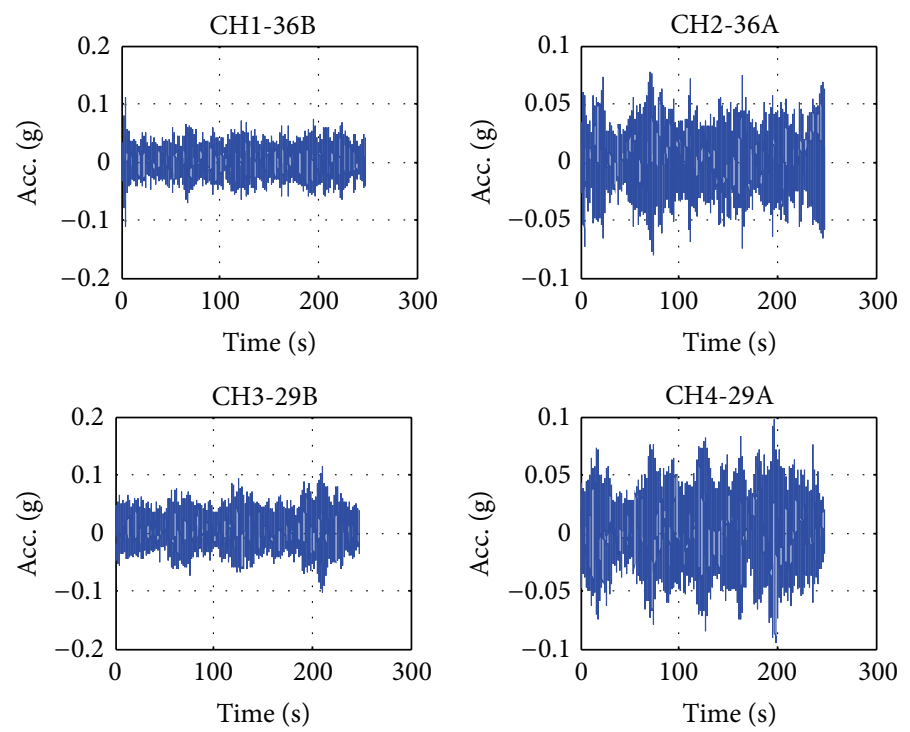

(a) Acceleration signals
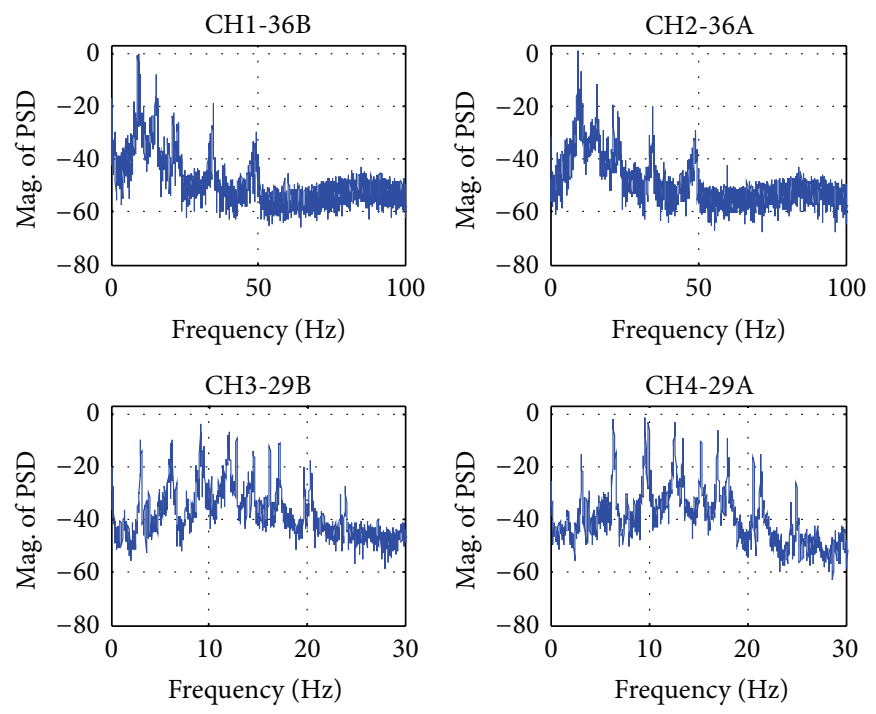

(b) Power spectral density

FIGURE 5: Measured accelerations and PSD data of hanger cables: (a) acceleration signals and (b) power spectral density.

TABLE 1: Geometrical and material properties of the hanger cables.

\begin{tabular}{|c|c|c|c|c|c|}
\hline Cable number & Length (m) & Diameter $(\mathrm{mm})$ & Young's modulus $\left(\mathrm{kN} / \mathrm{mm}^{2}\right)$ & Weight $\left(\mathrm{kN} / \mathrm{mm}^{3}\right)$ & Design tension $(\mathrm{kN})$ \\
\hline $29 \mathrm{~A}$ & 25.3234 & \multirow{4}{*}{49.52} & \multirow{4}{*}{$1.3734 \times 10^{2}$} & \multirow{4}{*}{$8.0 \times 10^{-8}$} & \multirow{4}{*}{377.685} \\
\hline $29 B$ & 24.9986 & & & & \\
\hline $36 \mathrm{~A}$ & 9.0173 & & & & \\
\hline $36 \mathrm{~B}$ & 8.8329 & & & & \\
\hline
\end{tabular}

of the two experiments to measure the natural frequencies that correspond to the symmetric mode of the hanger cables.

\section{Results of Tension Estimation}

In this study, the procedure for tension estimation using the FE model-based system identification method considered is shown in Figure 7. Further details can be found in Park et al. [5]. The identification variables in the FE model-based system identification method were the tensile force, axial stiffness, bending stiffness, and torsion stiffness of the cable and the clamp. A total of 9 variables were assumed.

Figure 8 shows the symmetrical mode of the final finite element model of the $36 \mathrm{~B}$ hanger cable in the FE model-based 


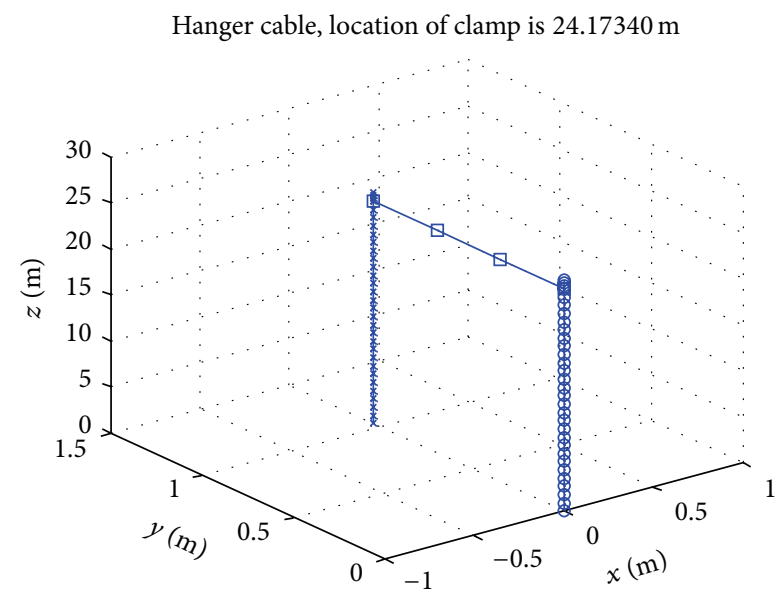

Figure 6: The finite element model of the hanger cable (29A).

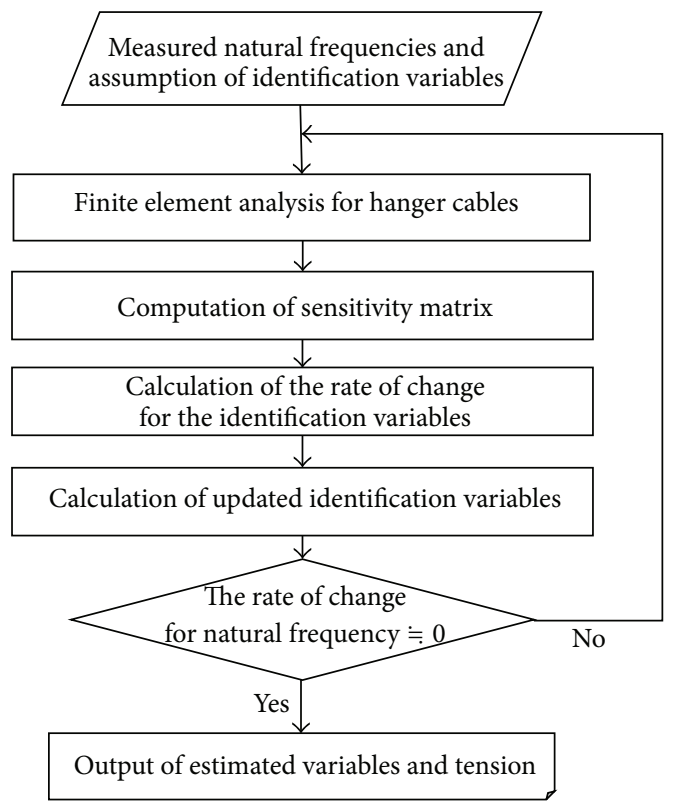

FIGURE 7: The procedure for tension estimation using the FE modelbased system identification method.

TABLE 2: The natural frequencies of symmetric modes of the hanger cables.

\begin{tabular}{lcccc}
\hline \multirow{2}{*}{ Symmetrical mode } & \multicolumn{4}{c}{ Measured frequency $(\mathrm{Hz})$} \\
& $29 \mathrm{~A}$ & $29 \mathrm{~B}$ & $36 \mathrm{~A}$ & $36 \mathrm{~B}$ \\
\hline 1st & 3.20 & 3.05 & 9.38 & 9.20 \\
2nd & 6.42 & 6.10 & 15.91 & 15.46 \\
3rd & 9.60 & 9.11 & 23.15 & 22.90 \\
4th & 12.63 & 12.05 & 34.82 & 34.78 \\
5th & 15.32 & 14.54 & 49.14 & 48.28 \\
\hline
\end{tabular}

system identification method. Table 3 shows the tension of each cable according to the estimation methods. Here, the methods by Kim et al. [6, 7] assumed the boundary conditions fixed at both sides and conducted formula-based inverse
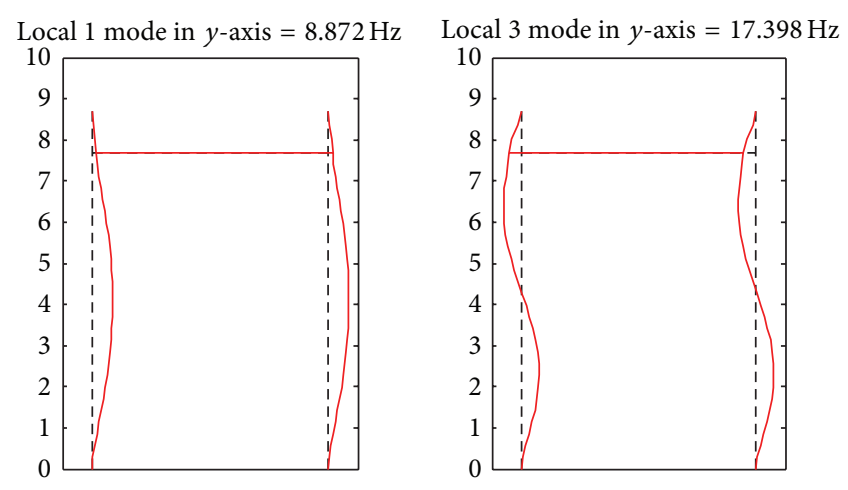

Local 5 mode in $y$-axis $=24.025 \mathrm{~Hz}$
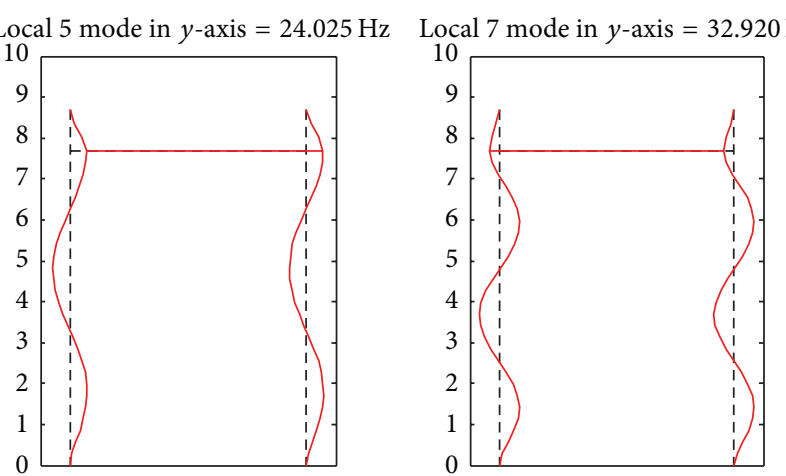

FIGURE 8: Symmetrical mode shapes of the final finite element model.

analysis in consideration of the mode participation factor, while, for the estimation of the tension using the FE modelbased system identification method, the boundary condition was defined as fixed at both sides. The 5 symmetrical modes' natural frequencies were used as the input measurement values as well. The taut string theory and linear regression method showed the estimation results of the tension force using (1) and (2), respectively. In this case, the taut string theory used the first symmetrical mode.

As shown in Figure 8, in the case of 36B cable, the 1st, 3rd, 5 th, and 7 th vibration modes in the perpendicular direction are the 1st, $2 \mathrm{nd}$, $3 \mathrm{rd}$, and 4 th symmetrical vibration modes, respectively. When estimating tension using the FE modelbased system identification method, as shown in (4) not only the tension of the cable but also other variables, such as the axial, flexural, and torsional rigidities, could be estimated. However, for the hanger cables, variations in the tension force are the main cause of changes to the natural frequency. The influences from other variables are not significant. This was confirmed by the sensitivity analysis of each variable by Park et al. [5]. Estimation of variables other than the tension using the cables of Gwang-An Bridge shows a similar result, too. Therefore, in this paper, the results of the tension estimation other than the other variables are only presented. In Table 3 , for the four hanger cables, the estimated tension by the FE model-based system identification method is smaller than those estimated by other methods. This phenomenon is even more significant with the shorter $36 \mathrm{~B}$ cable. As the length of the cable gets shorter, the estimated tension also appears to be smaller. On the other hand, the formula-based inverse 


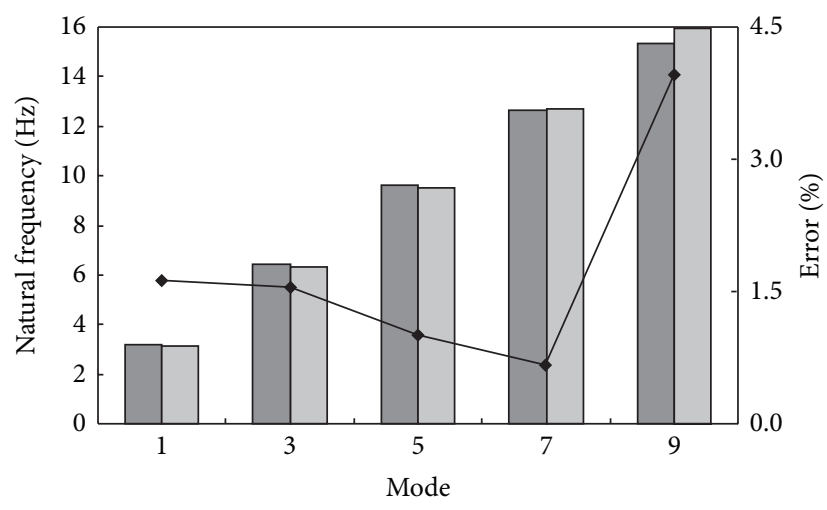

(a) Cable 29A (SRSS $=4.70 \%)$

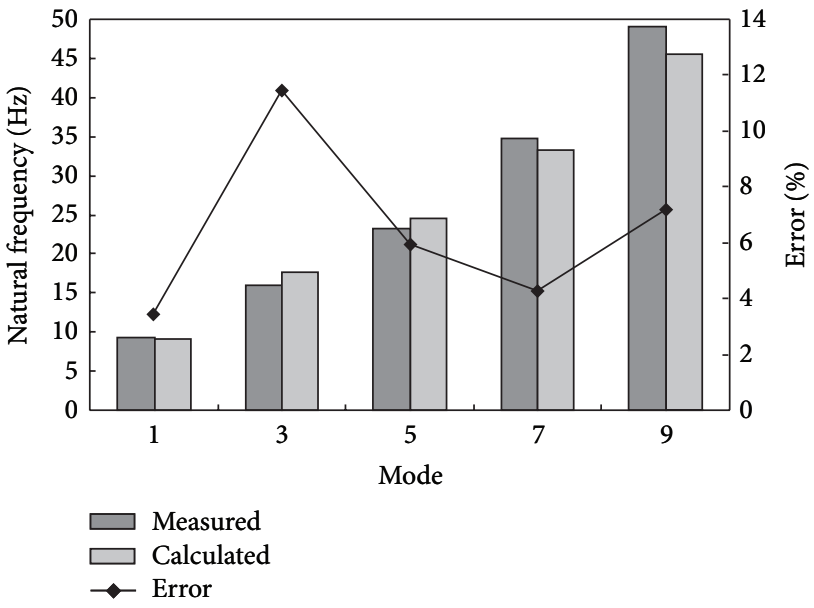

(c) Cable 36A (SRSS $=15.73 \%)$

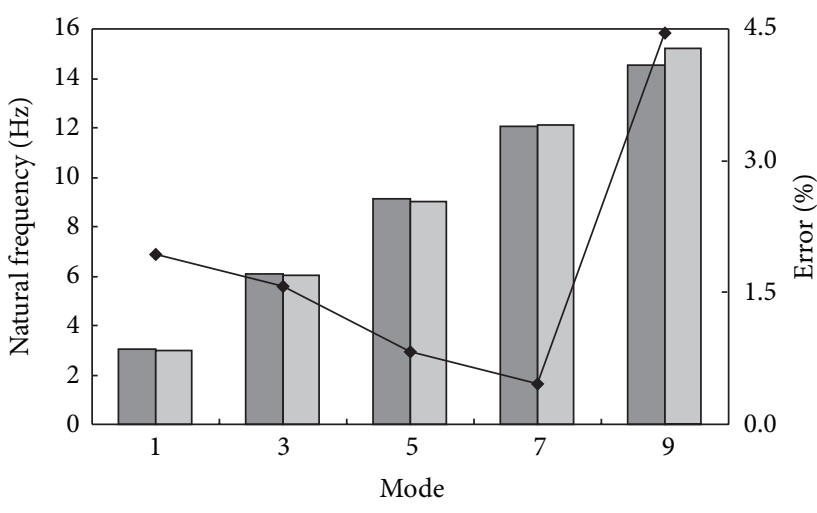

(b) Cable 29B (SRSS $=5.19 \%)$

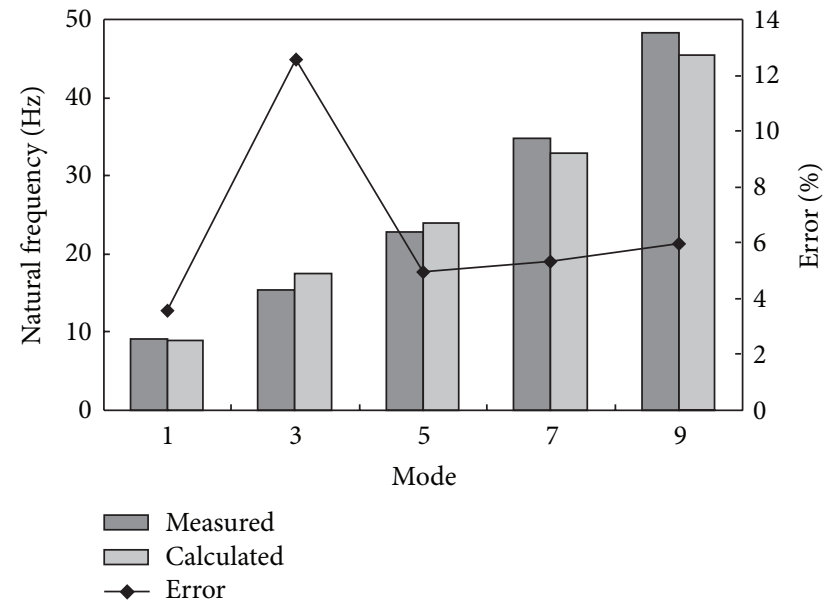

(d) Cable 36B (SRSS $=16.07 \%)$

FIGURE 9: Errors in the natural frequencies for the tension estimation using the FE model-based system identification method: (a) cable 29A $($ SRSS $=4.70 \%)$; (b) cable 29B $($ SRSS $=5.19 \%)$; (c) cable 36A (SRSS $=15.73 \%)$; and $(\mathrm{d})$ cable 36B $($ SRSS $=16.07 \%)$.

TABLE 3: The tensions $(\mathrm{kN})$ of each hanger cable according to the estimation methods.

\begin{tabular}{|c|c|c|c|c|}
\hline \multirow{2}{*}{ Tension estimation methods } & \multicolumn{4}{|c|}{ Cable number } \\
\hline & $29 \mathrm{~A}$ & 29B & $36 \mathrm{~A}$ & $36 \mathrm{~B}$ \\
\hline Design tension & \multicolumn{4}{|c|}{377.685} \\
\hline FE model-based system identification method & 355.82 & 309.92 & 287.79 & 256.58 \\
\hline Formula-based inverse analysis method & 393.45 & 342.75 & 384.45 & 349.86 \\
\hline Taut string theory & 402.35 & 355.54 & 412.60 & 382.73 \\
\hline Linear regression method & 397.75 & 348.68 & 321.70 & 294.74 \\
\hline
\end{tabular}

analysis method estimates the tension consistently regardless of the length of the cable. However, the cable tension of A group is estimated to be bigger than that of $\mathrm{B}$ group. The taut string theory method shows a similar pattern with the formula-based inverse analysis method but the deviations of the estimated tension between A and B group are significant. The linear regression method shows a reduction in the estimated tension as the cable became shorter as was the case with the FE model-based system identification method.
To check the reliability of the tension force measured by each of these methods, it would be necessary to use load cells to take actual measurements, which would then be compared to the estimations. However, since there are no load cells installed on the hanger cables numbers 29 and 36, it was not possible to determine the exact tension values at the time of the experiment. However, for methods of estimating the tension using inverse analysis and system identification techniques, the accuracy of estimated tension could be checked 


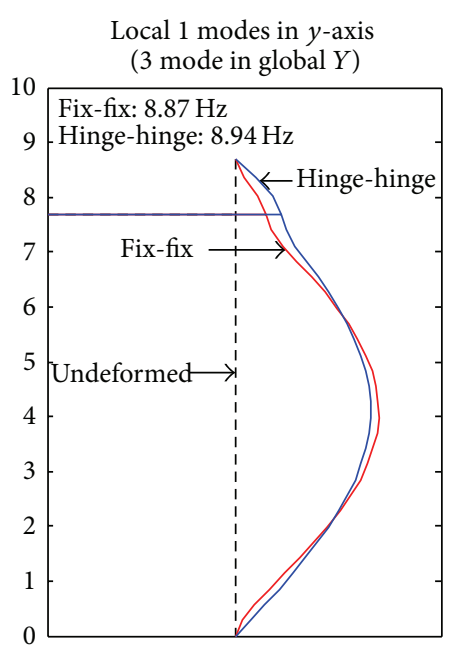

Local 5 mode in $y$-axis (10 mode in global $Y$ )

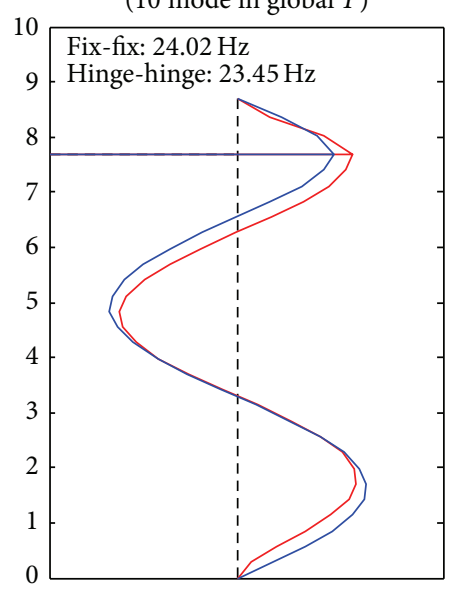

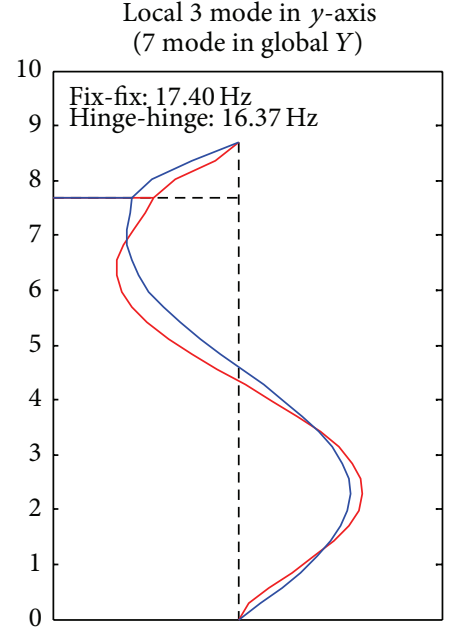

Local 7 mode in $y$-axis

(14 mode in global $Y$ )

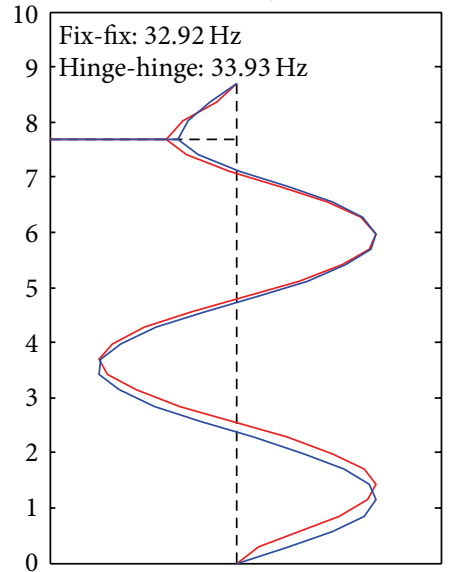

FIGURE 10: Symmetrical mode shapes according to the boundary conditions.

indirectly by means of the SRSS errors of the natural frequencies.

Figure 9 shows the errors in the natural frequencies for the tension estimation using the FE model-based system identification method for each of the hanger cables. As seen in the figure, hanger cable number 29 shows a relatively small error between the measured and calculated natural frequencies. However, the deviation for hanger cable number 36 appears to be significant. Therefore, the tension estimation results for the hanger cable number 36, where the error of the natural frequency is greater, are less reliable. This is because of the lower reliability of the measured natural frequencies, or the finite element model and the boundary conditions of the hanger cables are different from the actual conditions. However, measurement of the natural frequency can be relatively accurate compared to the results of Kim et al. [6,7]. The only physical difference between cables numbers 29 and 36 is the length, which causes the natural frequency to change. The change here is sensitive to the boundary conditions. Therefore, the influence from the boundary conditions should be assumed to be the cause of the relatively bigger error with cable number 36, and the influence of the boundary conditions should be analyzed.

\section{Sensitivity Analysis of the FE Model-Based System Identification Method Depending on the Input Conditions}

When estimating the tension force using the FE modelbased system identification method, basically, the errors in the natural frequency are minimized using the measured natural frequency and the calculated natural frequency from the finite element model. Therefore, it is exposed to the influence from the boundary conditions of the finite element model. In fact, to identify the boundary conditions of the hanger cables, it is necessary to extract the vibration modes experimentally. However, in this study, there were several limitations that forced us to install only one instrument to measure the acceleration on the hanger cable. Therefore, it was not possible to extract the forms of the vibration modes through experiments. 


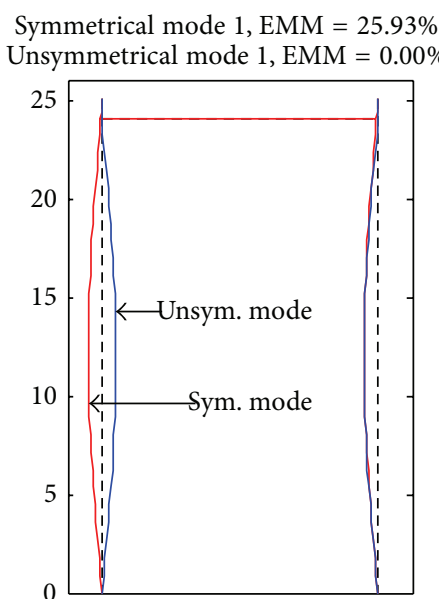

Symmetrical mode 2, EMM $=0.02 \%$

Unsymmetrical mode 2, EMM $=0.00 \%$

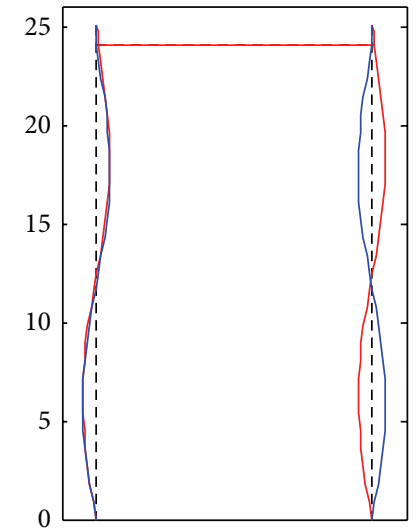

Symmetrical mode 3, EMM $=3.57 \%$

Unsymmetrical mode $3, \mathrm{EMM}=0.00 \%$

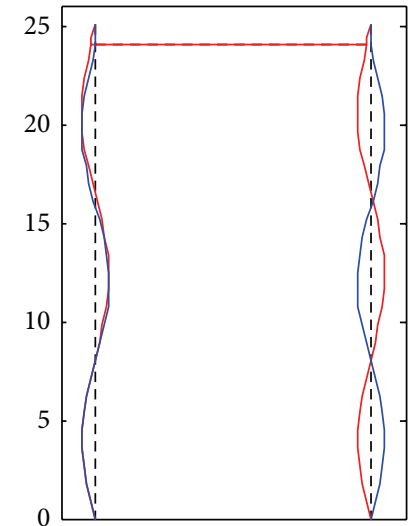

Symmetrical mode 4, EMM $=0.14 \%$

Symmetrical mode 5, EMM $=1.99 \%$ Unsymmetrical mode $4, \mathrm{EMM}=0.00 \%$

Unsymmetrical mode 5, EMM $=0.00 \%$
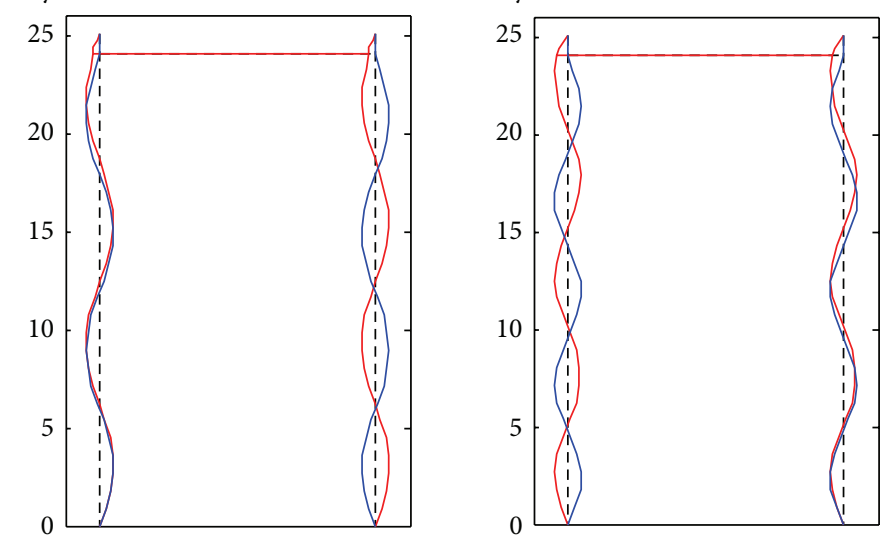

FIGURE 11: Mode shapes according to the boundary conditions.

TABLE 4: Results of the tension estimation using the FE model-based system identification method (hinges at both sides).

\begin{tabular}{|c|c|c|c|c|c|c|c|c|}
\hline Cable number & Frequency & 1 & 2 & 3 & 4 & 5 & SRSS (\%) & Tension $(\mathrm{kN})$ \\
\hline \multirow{3}{*}{$29 \mathrm{~A}$} & Measured (Hz) & 3.20 & 6.42 & 9.60 & 12.63 & 15.32 & \multirow{3}{*}{2.73} & \multirow{3}{*}{381.96} \\
\hline & Calculated (Hz) & 3.18 & 6.36 & 9.53 & 12.66 & 15.68 & & \\
\hline & Error (\%) & 0.79 & 0.91 & 0.73 & 0.25 & 2.33 & & \\
\hline \multirow{3}{*}{ 29B } & Measured (Hz) & 3.05 & 6.10 & 9.11 & 12.05 & 15.54 & \multirow{3}{*}{3.03} & \multirow{3}{*}{334.38} \\
\hline & Calculated (Hz) & 3.02 & 6.04 & 9.06 & 12.05 & 14.93 & & \\
\hline & Error (\%) & 1.04 & 0.87 & 0.52 & 0.00 & 2.66 & & \\
\hline \multirow{3}{*}{$36 \mathrm{~A}$} & Measured (Hz) & 9.38 & 15.91 & 23.15 & 34.82 & 49.14 & \multirow{3}{*}{8.31} & \multirow{3}{*}{363.89} \\
\hline & Calculated (Hz) & 9.12 & 16.77 & 23.90 & 24.28 & 47.00 & & \\
\hline & Error (\%) & 2.82 & 5.40 & 3.27 & 1.53 & 4.35 & & \\
\hline \multirow{3}{*}{$36 \mathrm{~B}$} & Measured (Hz) & 9.20 & 15.46 & 22.90 & 34.78 & 48.28 & \multirow{3}{*}{7.96} & \multirow{3}{*}{331.92} \\
\hline & Calculated (Hz) & 8.94 & 16.37 & 23.45 & 33.93 & 46.83 & & \\
\hline & Error (\%) & 2.83 & 5.87 & 2.42 & 2.44 & 3.00 & & \\
\hline
\end{tabular}

Table 4 shows the results of the tension estimation using the FE model-based system identification method when the boundary condition of the hanger cable was assumed as hinges at both sides.

As seen in the table, compared to the cases of fixed condition at both sides, errors in the natural frequency and
SRSS are reduced, while the estimated tension force is similar to that of the formula-based inverse analysis method. In particular, errors are reduced significantly with the number 36 hanger cable, which is shorter. This results in a subsequent larger change in the estimated tension force because the shorter cable is more sensitive to the boundary conditions 


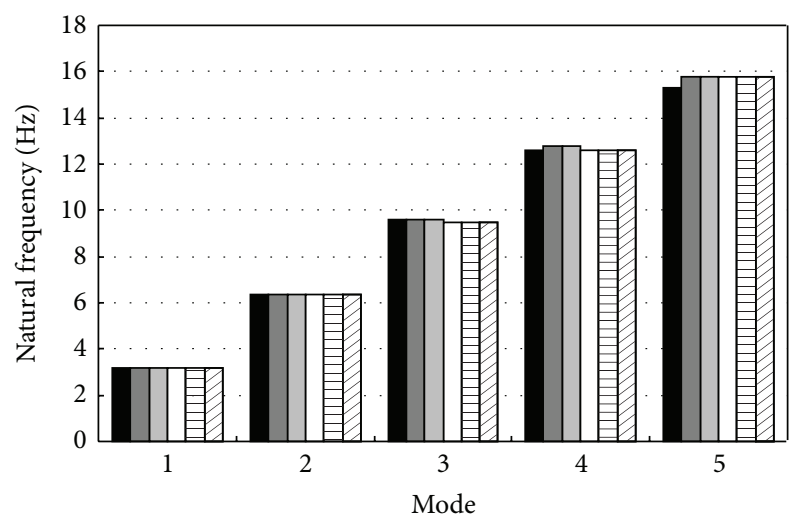

(a) Cable 29A

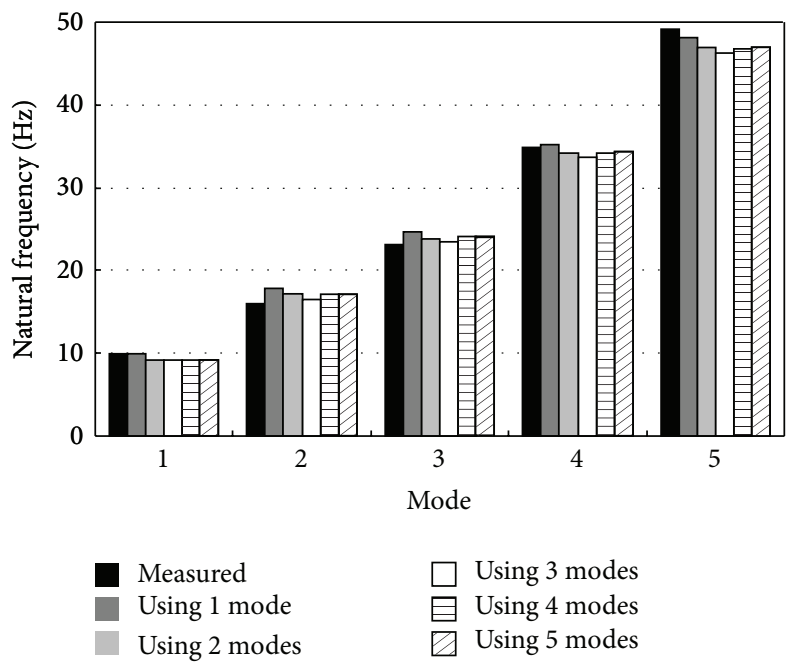

(c) Cable $36 \mathrm{~A}$

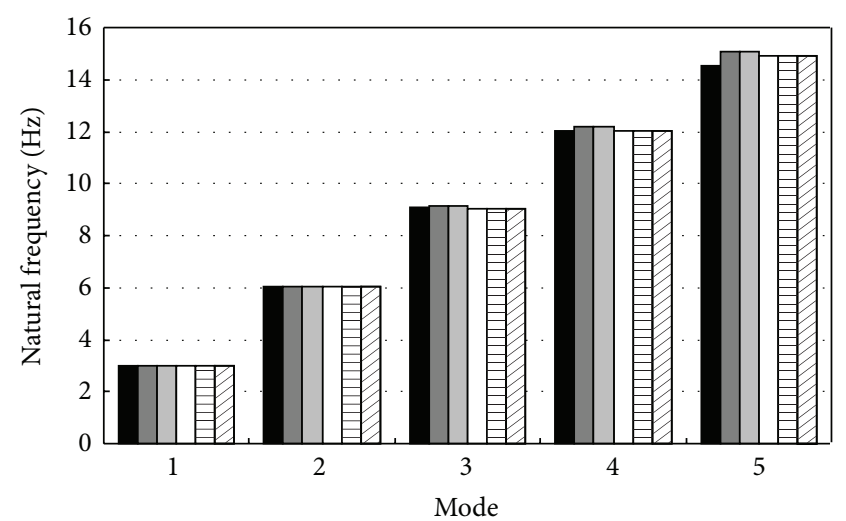

(b) Cable 29B

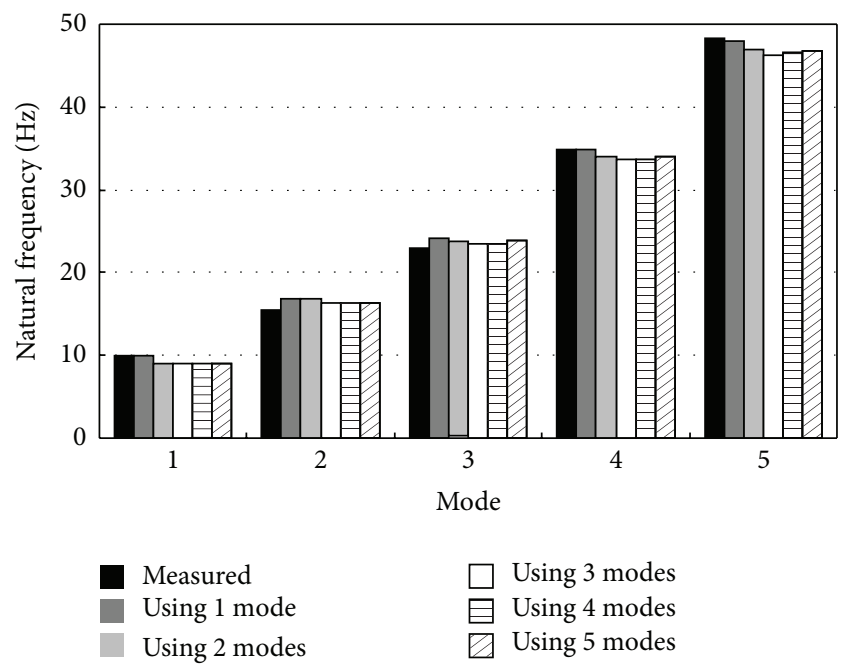

(d) Cable 36B

FIGURE 12: Changes of the natural frequencies according to the number of the input natural frequency.

compared to longer cables. Figure 10 shows the symmetrical mode shapes and natural frequency by the boundary conditions of $36 \mathrm{~B}$ cable.

As seen in the figure, the boundary condition influences the vibration mode and natural frequency significantly. Therefore, from the results of the tension estimation using the FE model-based system identification method, it is rationally assumed that the boundary conditions for this study with the hanger cables of Gwang-An Bridge should be hinges at both sides. This is different from the boundary condition of the inverse analysis, which was fixed at both sides. The reason for this difference is believed to be the differences in the finite element model, the input natural frequency value, and their numbers. Therefore, to identify the boundary conditions of the hanger cables more precisely, a number of acceleration measurement instruments to extract the vibration mode should be used and the boundary conditions be identified experimentally.

The tension estimation method using the FE model-based system identification method is affected not only by the accuracy of the finite element model, but also by the input natural frequency. Therefore, to consider natural frequency influence, the following method shown in the following is considered:

$$
\operatorname{EMM}(\%)=\frac{\left(\phi_{i}^{\mathrm{T}} M\{1\} / \phi_{i}^{\mathrm{T}} M \phi_{i}\right)}{M_{\text {total }}} \times 100,
$$

where each of the natural frequencies and effective modal mass (EMM) are calculated to use the natural frequency of the modes with higher effective modal mass in a sequential order. Then, the estimated tension force and the calculated natural frequency are analyzed.

Figure 11 shows the 10 natural vibration modes and their effective modal masses with cable 29A under the boundary condition of hinges at both sides and the design tension. As seen in the figure, the effective modal mass of the unsymmetrical mode was close to 0 . Therefore, the effective modal mass of each mode is considered and the results after applying $1,2,3,4$, and 5 natural frequencies starting from the one with the largest effective modal mass are compared. Table 5 shows the effective modal masses of vibration modes under hinges at both sides as the boundary condition and the design tension. 


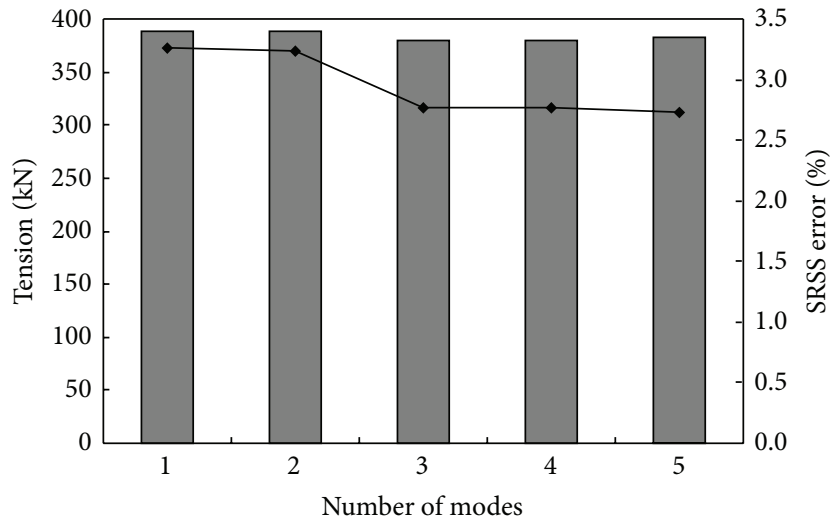

(a) Cable $29 \mathrm{~A}$

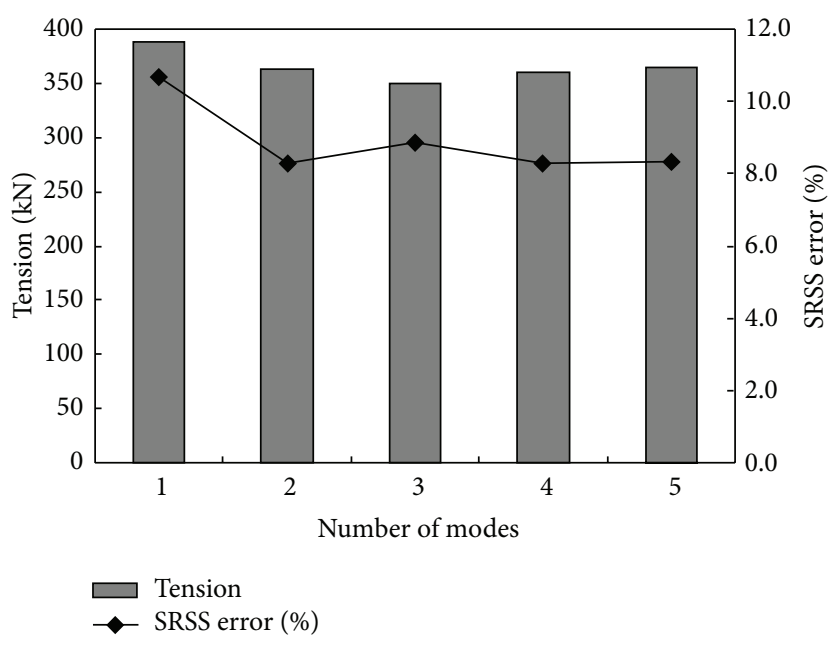

(c) Cable $36 \mathrm{~A}$

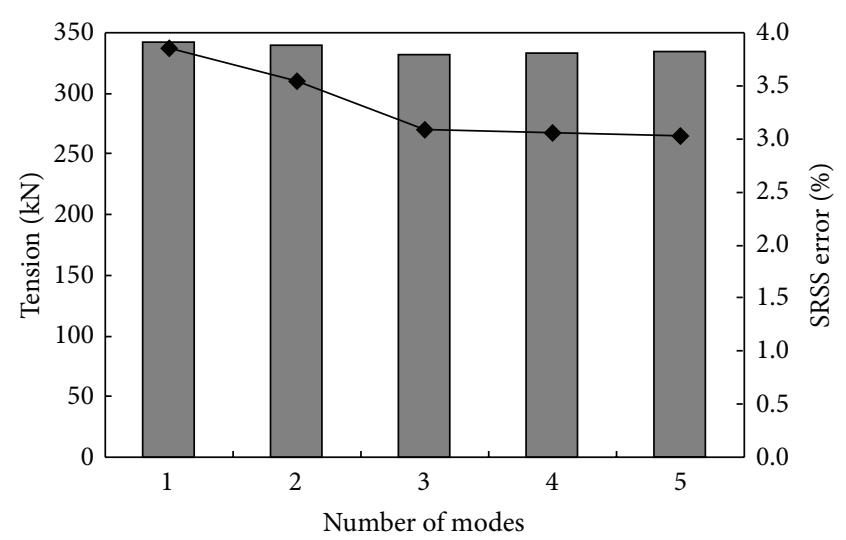

(b) Cable 29B

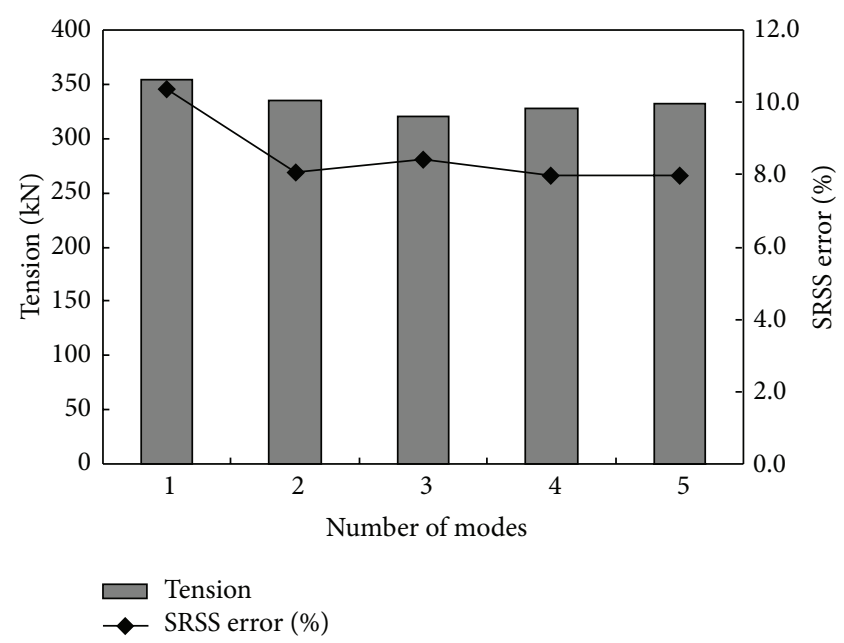

(d) Cable 36B

FIGURE 13: Changes of the SRSS errors in the natural frequency and the estimated tension according to the number of the input natural frequency.

As seen in Table 5, shorter cables have greater effective modal masses under the unsymmetrical mode, though the increase is not significantly large. For the symmetric mode, cable number 29 is bigger in the effective modal mass by the order of 1st, 3rd, 5th, 4th, and 2nd modes. However, for cable number 36, the effective modal mass is the largest in the order of 1st, 3rd, 2nd, 5th, and 4th. That is, the longer and shorter cables are generally similar in terms of overall effective modal masses. However, there are tiny differences depending on the influence from the unsymmetrical mode or the order of size of the effective modal masses.

Figures 12 and 13 show the natural frequencies, the SRSS errors in the natural frequency, and the estimated tension of the 5 symmetric modes of the final finite element model according to the input natural frequency for the FE modelbased system identification method. As seen in the figure, the changes in terms of the natural frequency of the final finite element model by the number of input natural frequencies in the FE model-based system identification method are not significant. In this case, as for cables 29A, 29B, 36A, and 36B, they show about $10 \%$ deviations for the design tension, which are $8.08,9.34,38.94$, and $34.24 \mathrm{kN}$, respectively. Therefore, if the tension is estimated using the FE model-based system identification method, it is possible to reliably estimate the tension using only the natural frequency of the small number of vibration modes with higher effective modal masses, which could be an advantage to using this method.

\section{Conclusion}

In this paper, the finite element model based method was applied to estimate the tension of hanger cables on GwangAn Bridge, and its reliability and applicability are investigated. The conclusion is as follows.

The taut string theory and the linear regression method, which are used to estimate the tension of normal cables, could render similar estimation results like the formulabased inverse analysis method and the system identification method based on the finite element models for cable number 29. However, for cable number 36, the results from these two methods differed significantly. Also, the existing methods could not be applied to various boundary conditions of cables, and it was not possible to verify the reliability unless the tensions were measured directly using load cells. On 
TABLE 5: Effective modal masses (\%) of each vibration mode.

\begin{tabular}{lcccc}
\hline Mode & $29 \mathrm{~A}$ & $29 \mathrm{~B}$ & $36 \mathrm{~A}$ & $36 \mathrm{~B}$ \\
\hline $\begin{array}{l}\text { (1st symmetrical } \\
\text { mode) }\end{array}$ & 25.9265 & 25.9176 & 27.1070 & 27.2265 \\
$\begin{array}{l}\text { (1st unsymmetrical } \\
\text { mode) }\end{array}$ & 0.0000 & 0.0000 & 0.0000 & 0.0000 \\
$\begin{array}{l}3 \text { (2nd symmetrical } \\
\text { mode) }\end{array}$ & 0.0237 & 0.0250 & 1.2822 & 1.2983 \\
$\begin{array}{l}4 \text { (2nd } \\
\text { unsymmetrical }\end{array}$ & 0.0000 & 0.0000 & 0.0000 & 0.0000 \\
$\begin{array}{l}\text { mode) } \\
5 \text { (3rd symmetrical }\end{array}$ & 3.5729 & 3.5950 & 3.5551 & 3.4151 \\
$\begin{array}{l}\text { mode) } \\
6 \text { (3rd unsymmetrical } \\
\text { mode) }\end{array}$ & 0.0000 & 0.0000 & 0.0001 & 0.0001 \\
$\begin{array}{l}7 \text { (4th symmetrical } \\
\text { mode) } \\
8 \text { (4th unsymmetrical }\end{array}$ & 0.1392 & 0.1473 & 0.1101 & 0.1227 \\
$\begin{array}{l}\text { mode) } \\
9 \text { (5th symmetrical } \\
\text { mode) }\end{array}$ & 1.9872 & 2.008 & 0.4461 & 0.4355 \\
$\begin{array}{l}10(5 \text { th } \\
\text { unsymmetrical } \\
\text { mode) }\end{array}$ & 0.0000 & 0.0000 & 0.0003 & 0.0004 \\
\hline
\end{tabular}

the other hand, the system identification technique allowed the boundary conditions to be taken into consideration easily, and the reliability of the tension estimation could indirectly be assessed by means of errors in the calculated natural frequency from actual measurements of the natural frequency. In addition to the tension, estimates could be made for variables such as the rigidities for cables and clamps. Since it is not sensitive to the number of the natural frequency inputs, the utility of this method is high.

The key to creating a finite element model is to introduce an appropriate boundary condition. Shapes of the vibration mode due to the change of the boundary condition are the same, but the size of the relative vibration mode at each node is different. Therefore, the vibration mode varies depending on the boundary conditions, and this difference becomes larger as it approaches the support. However, changes in the frequencies caused by the boundary conditions did not have a fixed tendency and varied in accordance with the order of the natural frequency. As the cable becomes shorter, it is influenced more by the boundary conditions. Therefore, it is necessary to extract the vibration mode to judge the boundary conditions experimentally.

For this reason, when the length of the cable was longer, not only the existing methods, but also the methods based on the finite element models for the hanger cables could be used. However, as the length decreased, the increase in errors in the existing method is inevitable, and the reliability of the tension estimation based on the finite element model is higher. However, the model-based tension estimation method is seriously influenced by the accuracy of the finite element model that includes the boundary conditions. Therefore, it is important to create an appropriate finite element model.

\section{Conflict of Interests}

The authors declare that there is no conflict of interests regarding the publication of this paper.

\section{Acknowledgments}

This research was supported by the Construction Core Technology Program funded by the Ministry of Construction \& Transportation of the Korean government (Grant no. 2006D20). The financial support is gratefully acknowledged.

\section{References}

[1] H. M. Irvine, Cable Structures, The MIT Press, Cambridge, Mass, USA, 1981.

[2] T. Shimada, A study on the maintenance and management of tension measurement for the cable of bridge [Ph.D. dissertation], Kobe University, 1995.

[3] J. K. Yun, J. Son, and S. P. Chang, "A study on tension measurement for cable-supported bridge," in Proceedings of the Annual Conference of The Korean Society of Civil Engineers, pp. 117-120, 1999.

[4] S. S. Ahn, I. K. Lee, I. H. Bae, and H. K. Choi, "Static test method for estimating tensile force of hanger cable," in Proceedings of Annual Conference of The Korean Society of Civil Engineers, pp. 1418-1423, 2003.

[5] T. Park, S. Moon, H. J. Joo, and B. H. Kim, "Estimating tensile force of hangers in suspension bridges using frequency based SI technique: I. Theory," Journal of The Korean Society of Civil Engineers, vol. 27, no. 2, pp. 165-172, 2007.

[6] B. H. Kim, S. Moon, I. H. Bae, and T. Park, "Estimating tensile force of hangers in suspension bridges using frequency based SI technique: II. field application," Journal of the Korean Society of Civil Engineers, vol. 27, pp. 173-179, 2007.

[7] N. S. Kim, D. W. Park, Y. M. Park, and J. H. Jeong, "Back analysis technique for the estimation of tension force on hanger cables," Jorunal of the Earthquake Engineering Society of Korea, vol. 21, no. 3, pp. 1-10, 2007.

[8] H. T. Jang, B. H. Kim, and T. Park, "Estimating tensile force of hangers in suspension bridges using frequency based SI technique: III. Experimental Verification," Journal of the Korean Society of Civil Engineers, vol. 28, no. 2A, pp. 215-222, 2008.

[9] M. S. Triantafyllou and L. Grinfogel, "Natural frequencies and modes of inclined cables," Journal of Structural Engineering New York, vol. 112, no. 1, pp. 139-148, 1986.

[10] J. C. Russell and T. J. Lardner, "Experimental determination of frequencies and tension for elastic cables," Journal of Engineering Mechanics, vol. 124, no. 10, pp. 1067-1072, 1998.

[11] T. Shimada, K. Kimoto, and S. Narui, "Study on estimating tension of tied hanger rope of suspension bridge by vibration method," Proceedings of JSCE, vol. 404, no. 11, pp. 455-458, 1989.

[12] H. Zui, T. Shinke, and Y. Namita, "Practical formulas for estimation of cable tension by vibration method," Journal of Structural Engineering, vol. 122, no. 6, pp. 651-656, 1996. 


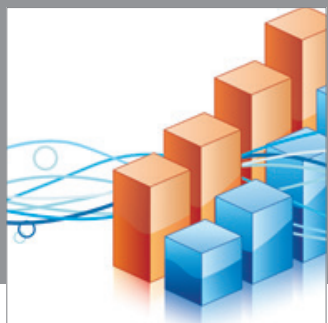

Advances in

Operations Research

mansans

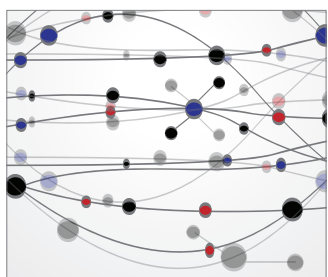

The Scientific World Journal
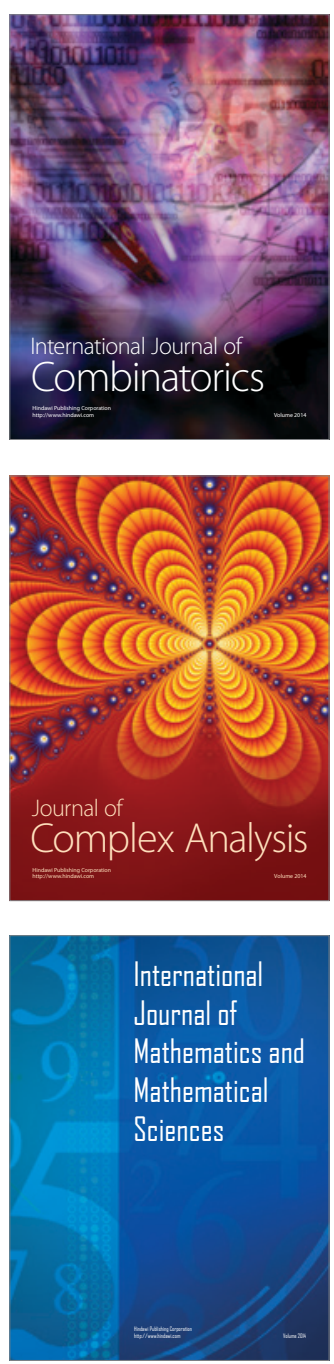
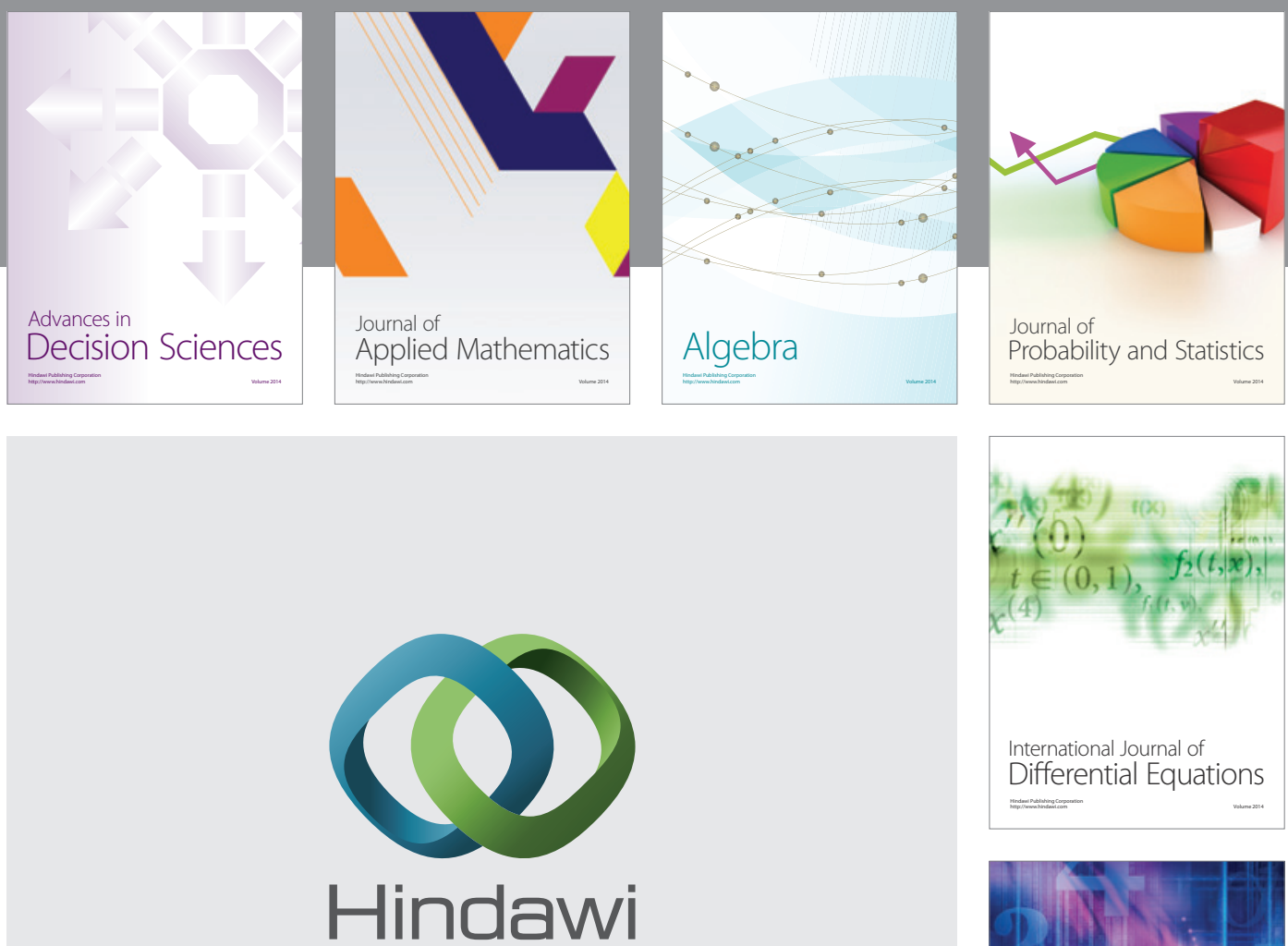

Submit your manuscripts at http://www.hindawi.com
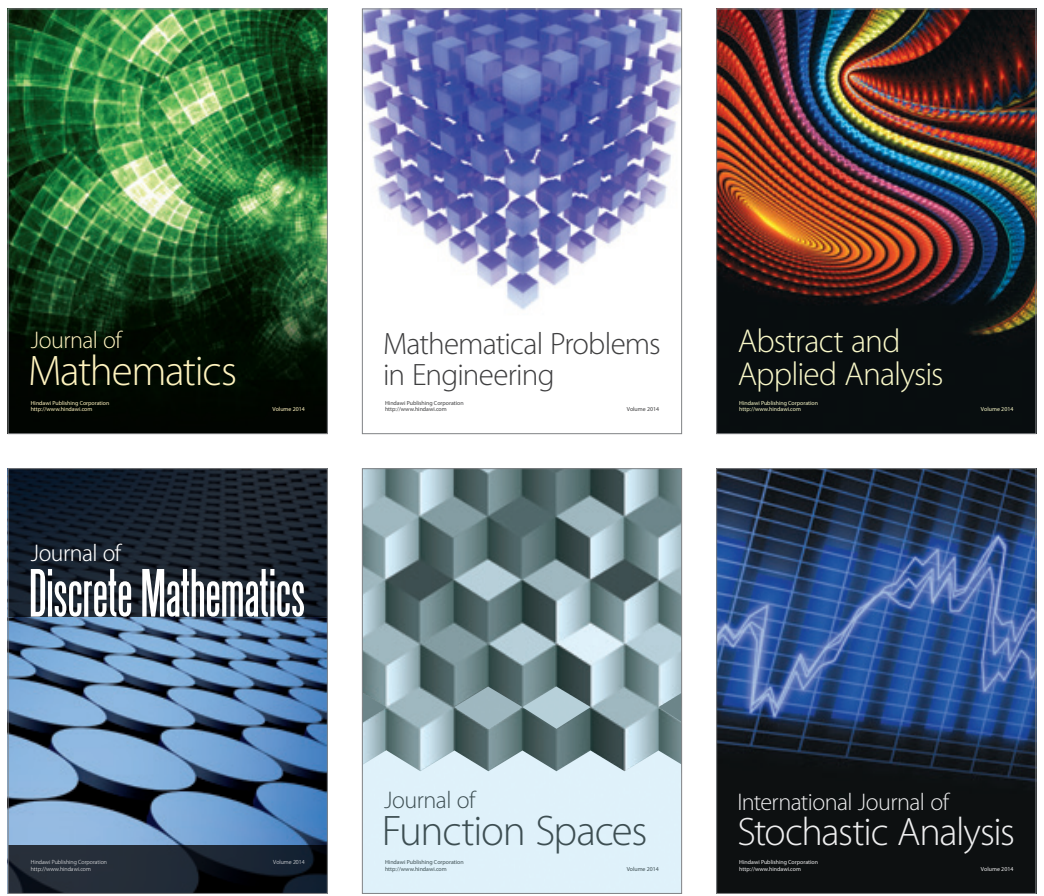

Journal of

Function Spaces

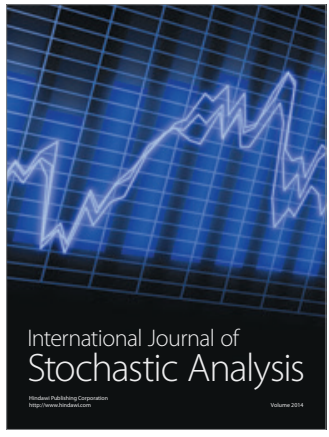

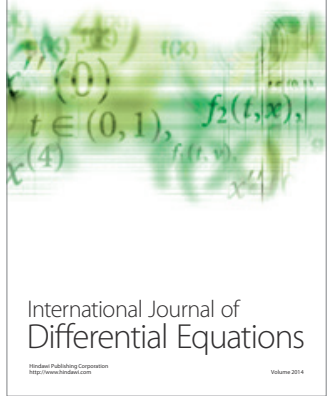
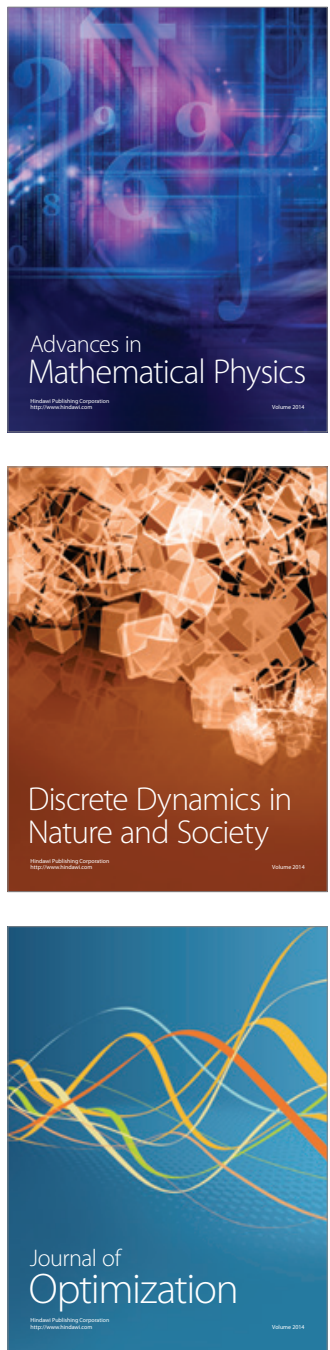